\title{
Prevalence of Intestinal Parasitic Infections among Patients Referring to Medical Diagnostic Laboratories, Kashan, Central Iran, 2015-2018
}

\author{
Shirin Khodabakhsh Arbat ${ }^{1}$, Hossein Hooshyar ${ }^{*}$, Hadi Sadeghi ${ }^{1}$ \\ 1Department of Parasitology, School of Medicine, Kashan University of Medical Sciences, Kashan, Iran
}

Received Nov. 19, 2018; Accepted Dec. 31, 2018

\begin{abstract}
Introduction: Intestinal parasitic infections are among the most common diseases worldwide and are significant indicators of the health status of communities, especially in developing countries. This study aims to determine the prevalence of intestinal parasites infection in patients referring to Kashan diagnostic laboratories from July 2015 to August 2018. Methods: This crosssectional study was carried out on 6921 patients referring to medical diagnostic laboratories, Kashan, central Iran. Fecal specimens were examined by direct smear and formalin-ether concentration methods. The results together with risk factors including sex, age were recorded and analyzed by descriptive statistics using SPSS 16 software. Results: Out of the 6921 individuals examined, $3636(52.5 \%)$ were male and $3285(47.5 \%)$ were female. Microscopy revealed the prevalence of parasitic infection by $4.96 \%(4.96 \pm 0.5)$. Totally $5.1 \%$ of males and $4.6 \%$ of females had intestinal parasite infections. No significant association was seen between sex, seasons, and parasite infections. Rate of infection to intestinal parasites were Blastocystis spp. (3.06\%), Entamoeba coli (0.95\%), Giardia intestinalis (0.59\%), Iodamoeba butschlii $(0.23 \%)$, Endolimax nana $(0.20 \%)$, Entamoeba hartmanni $(0.20 \%)$, Dientamoeba fragilis (0.14\%), Chilomastix mesnili (0.07\%), Entamoeba histolytica/Entamoeba dispar $(0.05 \%)$ and Hymenolepis nana $(0.01 \%)$ was the only intestinal worm that observed in one individual. The results showed that $4.48 \%$ of the examined individuals were infected with one parasite, $0.39 \%$ with two and $0.08 \%$ with 3 or more parasites. Conclusion: The prevalence of intestinal parasites in our study was lower than those from other areas of Iran and other countries, indicating an increase in health status as well as public awareness of infectious diseases. J Med Microbiol Infec Dis, 2018, 6 (2-3): 62-66.
\end{abstract}

Keywords: Prevalence, Intestinal parasites, Kashan, Iran.

\section{INTRODUCTION}

Intestinal parasitic infections are among the most common human infections worldwide and are considered as critical health indicators of a community, especially in developing countries [1]. According to the World Health Organization (WHO) report, more than two billion people in the world are infected with intestinal parasitic infections [2-3]. More than 1.5 billion (24\%) of the world's population are estimated to be infected with parasitic infections such as Ascaris lumbricoides, hookworms and Trichuris trichiura [4]. These infections are widespread mainly in tropical and subtropical regions. The highest incidences are reported from developing countries, more in sub-Saharan Africa, North and South America, China, and East Asia, where people are struggling with health problems, insufficient water supply, rapid population growth and other economic and social problems [4-6]. The most prominent pathogenic protozoa of human intestine are Giardia intestinalis, Entamoeba histolytica/Entamoeba dispar, Dientamoeba fragilis and Blastocystis sp. [3, 6]. Giardia intestinalis is one of the most common etiological agents of parasitic diarrhea in humans and animals. This parasite has a global distribution, and it is estimated that 280 million people are affected by this parasite worldwide [7]. The global prevalence of this protozoon in human has been estimated to be about 8 to $30 \%$ in developing countries and 1 to $8 \%$ in developed countries [8]. In Iran, like other developing countries, parasitic diseases in communities are considered as one of the critical health issues. Infection rates of giardiasis in different regions of Iran have been reported to be between $1.2 \%-38 \%$ [9].

Amoebiasis is the third leading cause of death by parasitic diseases around the world. According to WHO report, E. histolytica has infected 50 million people around the world and has contributed to about in 90-110 thousand deaths each year [10]. Blastocystis spp. are considered as common intestinal parasites in the world and were traced in the human and many animals intestine [11]. The prevalence of this parasite in developed countries ranges from $0.5 \%$ to $23 \%$ [12] while in some developing countries it exceeds to more than $60 \%$ [13-14]. In a systematic review study, the average rate of Blastocystis infection was reported to be $3 \%$ in Iran [15]. Dientamoeba fragilis is another most common intestinal parasites in humans with a global distribution; its prevalence varies from $0.9 \%$ to $82.9 \%$ in different countries,

${ }^{*}$ Correspondence: Hossein Hooshyar

Department of Parasitology, School of Medicine, Kashan

University of Medical Sciences, Kashan, Iran, 8715988141.

Email: hooshyar4@yahoo.com

Tel: +98 (31) $55540021 \quad$ Fax: +98 (31) 55541112 
depending on the diagnosis method and studied population [16-19]. Several studies in Iran indicated $D$. fragilis prevalence within the range of $1 \%$ to $10 \%[12,20]$.

In addition to the severe complications that may lead to death, intestinal parasite infections can have a negative impact on the humans' health status, especially children and seniors. Depending on the parasite load and host immune system, it can cause symptoms and various complications such as malnutrition, weight loss, iron deficiency, growth retardation in children, ileus, and appendicitis in patients.

Consumption of contaminated water and food is one of the common ways human acquire intestinal parasites [21]. Because Kashan city is one of the tourism zones of the country and a high number of tourists visit this city, parasitic infections of people is a critical issue in this city. Information on the prevalence of human infections and the common parasite species would assist health authorities to adopt proper measures to reduce infection rate and its distribution in this city. This study aims to determine the prevalence of intestinal parasites infection in patients referring to Kashan diagnostic laboratories within 20152018.

\section{MATERIAL AND METHODS}

Study area and sampling. Kashan City, covering an area of $4415.07 \mathrm{~km}^{2}$, is in the center of Iran, north of Isfahan Province between $50^{\circ} 55^{\prime}$ - 52 $22^{\circ}$ ' east longitude and $33^{\circ} 30^{\prime}-34^{\circ} 27^{\prime}$ north latitude along Kavir desert. Due to a gradient of altitude, this city has two relatively different climates; the moderate climate in mountainous areas and hot and arid climate in deserts. The annual precipitation of this city is $45.61 \mathrm{~mm}$, and its annual average temperature is $19.7^{\circ} \mathrm{C}$. This cross-sectional study was carried out on 6921 individuals who referred to Kashan medical diagnostic laboratories from July 2015 to August 2018. The demographic data of the subjects including sex, age and season were recorded in the questionnaires.

Stool examination. One fresh stool sample was collected, and direct stool smear technique was first employed to examine present protozoan trophozoite (X400). Then, to enhance the accuracy of the test, formalin-Ethyl acetate concentration technique was used followed by Lugol staining.

Statistical analysis. The results and data of each were registered and entered into a spss 16 software, and finally analyzed by Chi-Square and Fischer statistical test. The confidence interval was calculated and $P$-value $<0.05$ was considered significant. The information of the participants was kept entirely confidential, and each was defined with a code in the study.

Ethical consideration. This study was approved by Research Ethics Committee, Kashan University of Medical Sciences, Iran (Ethics code: IR.KAUMS.MEDNT.REC.1396.118).

\section{RESULTS}

Out of 6921 participants, 3636 were male (52.5\%), and 3285 female (47.5\%). Microscopy revealed the prevalence of parasitic infection by $4.96 \%(4.96 \pm 0.5)$. Only, one person $(0.01 \%)$ was infected with the helminth Hymenolepis nana, and the rest with protozoan infections. Totally $5.1 \%$ of males and $4.6 \%$ of females had intestinal parasite infections, and no significant relationship was seen between age and infections $(\mathrm{P}<0.05)$, or sex and intestinal parasites $(\mathrm{P}=0.34)$.

The intestinal protozoan infection rates included Blastocystis Sp. 212 (3.06\%), Entamoeba coli 66 (0.95\%), G. intestinalis 41 (0.59\%), Iodamoeba butschlii 16 (0.23\%), Endolimax nana 14 (0.20\%), Entamoeba hartmanni 14 (0.20\%), D. fragilis 10 (0.14\%), Chilomastix mesnili 5 (0.079\%), E. histolytica/E.dispar $4(0.05 \%)$ and H. nana 1 $(0.01 \%)$ (Table 1$)$. The most prevalent protozoan parasite was Blastocystis. This parasite also was the most common organism in multiple infections. In this investigation, 306 $(4.48 \%)$ of the individuals were infected by one parasite, 27 $(0.39 \%)$ with two and $6(0.08 \%)$ with 3 or more parasites (Figure 1). The average age among infected individuals was $37.02 \pm 1.08$ years (age range: $31-40$ ) (Table2). The highest frequency of parasitic infection was in spring (38.9\%) and lowest in autumn (15.6\%). There was no statistically significant difference between infection rates and seasons $(\mathrm{P}>0.05)$.

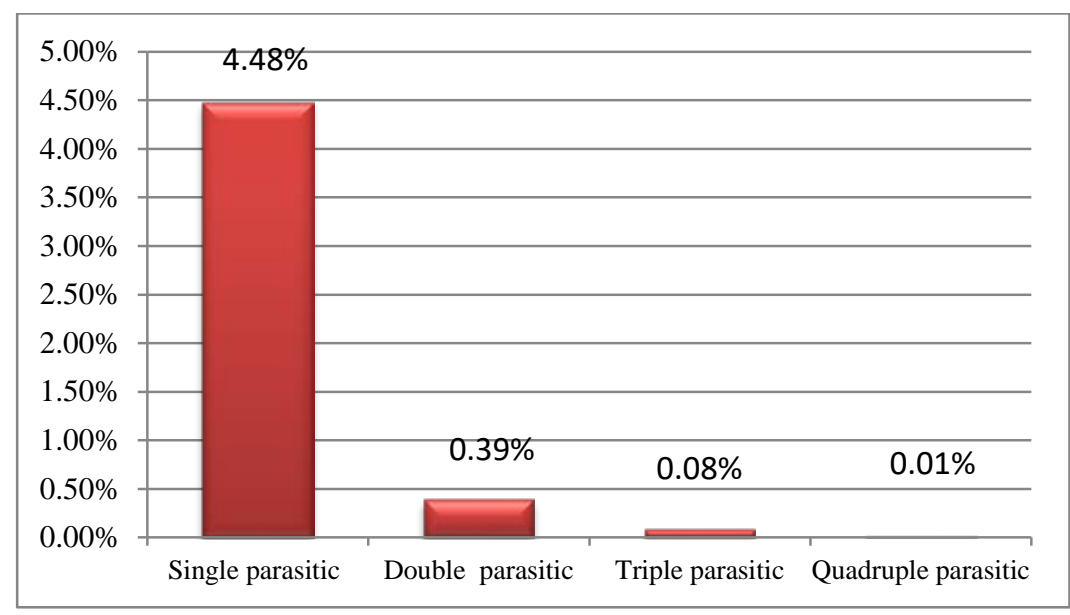

Fig. 1. Frequency of single and multiple parasites infections among patients referring to medical laboratories, Kashan, Iran 2015 -2018 
Table 1. Prevalence of intestinal parasitic infections and the rate of multiple infections among patients referring to medical laboratories of Kashan, central Iran (2015-2018)

\begin{tabular}{|c|c|c|}
\hline \multirow{2}{*}{ Parasite species } & \multicolumn{2}{|c|}{ Frequency } \\
\hline & No. & $(\%)$ \\
\hline \multicolumn{3}{|l|}{ Single infection } \\
\hline Blastocystis sp. & 187 & 2.7 \\
\hline E. coli & 54 & 0.78 \\
\hline G.intestinalis & 38 & 0.54 \\
\hline I. butschlii & 11 & 0.15 \\
\hline E. nana & 1 & 0.01 \\
\hline E. hartmanni & 8 & 0.11 \\
\hline D. fragilis & 7 & 0.10 \\
\hline Ch. mesnili & 3 & 0.04 \\
\hline H. nana & 1 & 0.01 \\
\hline Total & 310 & 4.48 \\
\hline \multicolumn{3}{|l|}{ Double infection } \\
\hline Blastocystis sp. + E. coli & 9 & 0.13 \\
\hline Blastocystis sp. + E. nana & 7 & 0.10 \\
\hline Blastocystis sp. + G.intestinalis & 3 & 0.04 \\
\hline Blastocystis sp. + D. fragilis & 2 & 0.02 \\
\hline Blastocystis sp. + E. hartmanni & 1 & 0.01 \\
\hline D. fragilis + E. nana & 1 & 0.01 \\
\hline E. coli + I. butschlii & 1 & 0.01 \\
\hline E. coli + E. hartmanni & 1 & 0.01 \\
\hline E. nana+ E. hartmanni & 1 & 0.01 \\
\hline E. nana+ Ch. mesnili & 1 & 0.01 \\
\hline Total & 27 & 0.39 \\
\hline \multicolumn{3}{|l|}{ Triple and quadruple parasitic } \\
\hline Blastocystis sp. + I. butschlii + E. histolytica/E. dispar & 2 & 0.02 \\
\hline E. histolytica/E. dispar + E. hartmanni + I. butschlii & 1 & 0.01 \\
\hline E. hartmanni+ I. butschlii + E. nana & 1 & 0.01 \\
\hline E. nana + E. coli + Ch. mesnili & 1 & 0.01 \\
\hline Blastocystis sp. + E. histolytica/E. dispar + E. hartmanni + E. nana & 1 & 0.01 \\
\hline Total & 6 & 0.08 \\
\hline
\end{tabular}

Table 2. Distribution of intestinal parasites among age groups referring to medical laboratories of Kashan, central Iran (2015-2018)

\begin{tabular}{|c|c|c|c|c|c|c|c|c|}
\hline \multirow[b]{2}{*}{ Parasite species } & \multicolumn{8}{|c|}{ Age groups } \\
\hline & $\begin{array}{c}<10 \\
\text { No. (\%) }\end{array}$ & $\begin{array}{c}11-20 \\
\text { No. (\%) }\end{array}$ & $\begin{array}{c}21-30 \\
\text { No. (\%) }\end{array}$ & $\begin{array}{c}31-40 \\
\text { No. (\%) }\end{array}$ & $\begin{array}{c}41-50 \\
\text { No. (\%) }\end{array}$ & $\begin{array}{c}51-60 \\
\text { No. (\%) }\end{array}$ & $\begin{array}{c}>60 \\
\text { No. }(\%)\end{array}$ & $\begin{array}{c}\text { Total } \\
\text { No. (\%) }\end{array}$ \\
\hline Blastocystis sp. & $23(30.84 \%)$ & $21(9.90 \%)$ & 37 (17.45\%) & 42 (19.81\%) & $32(15.09 \%)$ & $29(13.67 \%)$ & $28(13.20 \%)$ & 212 (100\%) \\
\hline E. coli & $11(16.66 \%)$ & $4(6.06 \%)$ & $7(10.60 \%)$ & $7(10.60 \%)$ & $10(15.15 \%)$ & $15(22.72 \%)$ & $12(18.18 \%)$ & $66(100 \%)$ \\
\hline G. intestinalis & 12 (29.46\%) & $3(7.31 \%)$ & $10(24.39 \%)$ & 8 (19.51\%) & $3(7.31 \%)$ & $4(9.75 \%)$ & $1(2.43 \%)$ & $41(100 \%)$ \\
\hline I. butschlii & $0(0 \%)$ & $2(12.5 \%)$ & $3(18.75 \%)$ & $4(25 \%)$ & $2(12.5 \%)$ & $2(12.5 \%)$ & $3(8.75 \%)$ & $16(100 \%)$ \\
\hline E. nana & $0(0 \%)$ & $0(0 \%)$ & $1(7.14 \%)$ & $5(35.71 \%)$ & $2(14.28 \%)$ & $5(35.71 \%)$ & $1(7.14)$ & $14(100 \%)$ \\
\hline E. hartmanni & $0(0 \%)$ & $2(14.3 \%)$ & $3(21.42 \%)$ & $6(42.85 \%)$ & $2(14.28 \%)$ & $1(7.14 \%)$ & $0(0 \%)$ & $14(100 \%)$ \\
\hline D. fragilis & $1(10 \%)$ & $1(10 \%)$ & $1(10 \%)$ & $2(20 \%)$ & $1(10 \%)$ & $2(20 \%)$ & $2(20 \%)$ & $10(100 \%)$ \\
\hline Ch. mesnili & $0(0 \%)$ & $0(0 \%)$ & $2(40 \%)$ & $1(20 \%)$ & $0(0 \%)$ & $1(20 \%)$ & $1(20 \%)$ & $5(100 \%)$ \\
\hline $\begin{array}{l}\text { E. histolytica/E. } \\
\text { dispar }\end{array}$ & $0(0 \%)$ & $1(25 \%)$ & $1(25 \%)$ & $0(0 \%)$ & $0(0 \%)$ & $1(25 \%)$ & $1(25 \%)$ & $4(100 \%)$ \\
\hline H. nana & $0(0 \%)$ & $0(0 \%)$ & $0(0 \%)$ & $0(0 \%)$ & $1(100 \%)$ & $0(0 \%)$ & $0(0 \%)$ & $1(100 \%)$ \\
\hline Total & $46(12.01 \%)$ & 34 (11.2\%) & 66 (17.23\%) & 75 (19.58\%) & $53(13.83 \%)$ & $60(15.66 \%)$ & 49 (12.79\%) & $383(100 \%)$ \\
\hline
\end{tabular}

\section{DISCUSSION}

In our study, $4.96 \%$ were infected, and nine species of protozoan and only one species of worm infection (H. nana) were observed. This finding is consistent with the recent studies in Iran showing a decline in intestinal helminths human infection [22]. Previous studies in Iran during 2005 2016 revealed that the prevalence of intestinal parasites was between $4.7 \%$ and $19.7 \%$ [23-27]. Another study on the incidence of intestinal parasites in Haftkel County, Southwest of Iran, in 2017, showed that $4.8 \%$ of individuals were harbored one of the human intestinal helminths or protozoa [28]. Also, a study in Bandar Abbas, southern Iran showed that the prevalence of intestinal parasites in primary school children was $6.5 \%$ which is consistent with the findings of our study [24]. However, in Hamedan Province,
Iran, the prevalence of intestinal parasites showed to be much higher than (35.1\%) [1] what we obtained in this study. In general, intestinal parasitic infections have decreased compared to previous decades in Iran. This decrease can be attributed to the improved health and treatment status of the people as well as their increased awareness and knowledge of infectious diseases. In this study, the prevalence of protozoan infection was more than that of intestinal helminths. In contrast to helminths ova, cyst of intestinal protozoa are more likely to be infectious immediately after release in the environment and are transmitted faster.

The most common intestinal protozoan identified in this study was Blastocystis sp. (3.06\%), while in a recent study in Haftkel, the most common one was G. intestinalis 
(3.16\%) [28]. In an investigation in Sari, the prevalence of intestinal parasites was $15.5 \%$ with the highest and lowest rates belonging to G.intestinalis (9.53\%) and I. butschlii (0.5\%), respectively, and $H$. nana $(0.3 \%)$ as the only intestinal worm infection [29]. Also, in northwestern Ethiopia, the diversity of parasitic worm was higher than intestinal protozoa [30-31]. In these studies, intestinal pathogenic protozoa, E. histolytica, and G.intestinalis and intestinal worms, like $H$. nana and A. lumbricoides, $S$. stercoralis, T. trichiura, Schistosoma mansoni, and Taenia sp. were reported [30-31].

In our study, the most prevalent parasitic infection was among the age group of 31-40 years old, followed by the age group 21-30 years old. In a similar study, the highest parasitic infection rate was in the age group of 20-40 years old (30). This may be due to the similarity of population condition in both studies. In agreement with previous studies [8], our study also revealed the highest levels of $G$. intestinalis infection in children $\leq 10$ years old and then in the 21-30 age group. Children in developing countries are more likely to be exposed to $G$. intestinalis infection due to poor public health conditions. In conclusion, the prevalence of intestinal parasites in our study is lower than those reported in other areas in Iran and other countries. Generally, in comparison with the results of a previous study in this city (2007-2011) that reported the intestinal parasitic infections as $7.6 \%$ [32], our study revealed a decrease in the prevalence rate, indicating an improvement of health status, and people awareness and improvement of environmental facilities in semi-urban areas.

\section{ACKNOWLEDGEMENT}

The authors would like to appreciate M. Arbabi for his assistance, and all individuals who voluntarily participated in this study. This study was financially supported by ViceChancellor of Research, Kashan University of Medical Sciences, Kashan, Iran (Grant No. 96224).

\section{CONFLICT OF INTEREST}

The authors declare that there are no conflicts of interest associated with this manuscript.

\section{REFERENCES}

1. Jafari R, Fallah M, Darani HY, Yousefi HA, Mohaghegh MA, Latifi M, et al. Prevalence of intestinal parasitic infections among rural inhabitants of Hamadan city, Iran, 2012. Avicenna J Clin Microbiol Inf. 2014; 1 (2). e21445.

2. Curval LG, de Oliveira França A, Fernandes HJ, Mendes RP, de Carvalho LR, Higa MG, et al. Prevalence of intestinal parasites among inmates in Midwest Brazil. Public Lib Sci One. 2017; 12 (9): e0182248.

3. World Health Organization. Library Cataloguing-inPublication Data. Neglected tropical diseases, hidden successes, emerging opportunities [Cited 2018 Dec 31] Available from: http://www.who.int/iris/handle/10665/44214.

4. Dudlová A, Juriš $\mathrm{P}$, Jurišová $\mathrm{S}$, Jarčuška $\mathrm{P}$, Krčméry $\mathrm{V}$. Epidemiology and geographical distribution of gastrointestinal parasitic infection in humans in Slovakia. Helminthologia. 2016; 53 (4): 309-17.

5. Pullan RL, Smith JL, Jasrasaria R, Brooker SJ. Global numbers of infection and disease burden of soil-transmitted helminth infections in 2010. Parasites Vec. 2014; 7 (1): 37.

6. Mohammed K, Abdullah MR, Omar J, Eugene II, Ismail A. Intestinal Parasitic Infection and Assessment of Risk Factors in North-Western, Nigeria: A Community Based Study. Int J Pharm Med Bio Sci. 2015; 4 (2): 141.

7. Gasparinho C, Ferreira FS, Mayer AC, Mirante MC, Vaz Nery S, Santos-Reis A, Portugal-Calisto D, Brito M. Molecular characterization of Giardia lamblia in children less than 5 years of age with diarrhoea attending the Bengo General Hospital, Angola. Trans Roy Soc Trop Med Hyg. 2017; 111 (11): 497-503.

8. Smith HV, Mank TG. Diagnosis of human Giardiasis. In: Lujan HD, Svard S, Editors. Giardia a model organism. Springer-Verlag/Wien, New York. 2011; 353-74.

9. Hooshyar H, Ghafarinasab S, Arbabi M, Delavari M, Rasti S. Genetic variation of Giardia lamblia isolates from food-handlers in Kashan, central. Iran J Parasitol. 2017; 12 (1): 83-9

10. Ben Ayed L, Sabbahi S. Entamoeba histolytica. Global Water Pathogens Project. http://www. waterpathogens. org (R. Fayer and W. Jakubowski,(eds) Part 3 Protists) www. waterpathogens.org/book/entamoeba-histolytica Michigan State University, E. Lansing, MI, UNESCO; 2017.

11. Wongthamarin K, Siricharoenthai P, Ountaveesap M, Tangpanitansook S, Mungthin M, Piyaraj P. Drinking unboiled water is the risk factor of Blastocystis incidence in rural community Thailand from prospective cohort study. Rev'Épidémiol Santé Pub. 2018; 66: S391.

12. Edrissian GhH, Rezaeian M, Ghorbani M, Keshavarz H, Mohebali M. Medical Parasitology (2th ed). Tehran: Ideh navin Press; 2015; 162.

13. Khoshnood S, Rafiei A, Saki J, Alizadeh K. Prevalence and Genotype Characterization of Blastocystis hominis Among the Baghmalek People in Southwestern Iran in 2013-2014. Jundishapur J Microbiol. 2015: 8 (10): e23930.

14. Salehi R, Haghighi A, Stensvold CR, Kheirandish F, Azargashb E, Raeghi S, et al. Prevalence and subtype identification of Blastocystis isolated from humans in Ahvaz, Southwestern Iran. Gastroenterol Hepatol from Bed to Bench 2017; 10 (3): 235-41.

15. Badparva E, Ezatpour B, Mahmoudvand H, Behzadifar M, Kheirandish F. Prevalence and Genotype Analysis of Blastocystis hominis in Iran: A Systematic Review and Meta Analysis. Arch Clin Inf Dis. 2017; 12 (1): e36648.

16. Ögren J, Van Nguyen S, Nguyen MK, Dimberg J, Matussek A. Prevalence of Dientamoeba fragilis, Giardia duodenalis, Entamoeba histolytica/dispar, and Cryptosporidium spp in Da Nang, Vietnam, detected by a multiplex real-time PCR. Acta Pathol Microbiol Immunol Scand. 2016; 124 (6): 529-33.

17. Garcia LS. Dientamoeba fragilis, one of the neglected intestinal Protozoa. J Clin Microbiol. 2016; 6: JCM-00400.

18. Stark D, Beebe N, Marriott D, Ellis J, Harkness J. Prospective study of the prevalence, genotyping, and clinical relevance of Dientamoeba fragilis infections in an Australian population. J Clin Microbiol. 2005; 43 (6): 2718-23. 
19. Preiss U, Ockert G, Brömme S, Otto A. Dientamoeba fragilis infection, a cause of gastrointestinal symptoms in childhood. Klin Pädia. 1990; 202 (02): 120-3.

20. Hemmati N, Razmjou E, Hashemi-Hafshejani S, Motevalian A, Akhlaghi L, Meamar AR. Prevalence and Risk Factors of Human Intestinal Parasites in Roudehen, Tehran Province, Iran. Iran J Parasitol. 2017; 12 (3): 364.

21. Lihua Xiao, Una Ryan, Yaoyu Feng. Biology of Foodborne Parasites, 2015; 53-76.

22. Rokni MB. The present status of human helminthic diseases in Iran. Annals Trop Med Parasitol. 2008; 102 (4): 283-95.

23. Sarkari B, Hosseini G, Motazedian MH, Fararouei M, Moshfe A. Prevalence and risk factors of intestinal protozoan infections: a population-based study in rural areas of BoyerAhmad district, Southwestern Iran. Bio Med Cen Inf Dis. 2016; 16 (1): 703.

24. Turki H, Hamedi Y, Heidari-Hengami M, Najafi-Asl M, Rafati S, Sharifi-Sarasiabi K. Prevalence of intestinal parasitic infection among primary school children in southern Iran. J Parasitic Dis. 2017; 41 (3): 659-65.

25. Badparva E, Kheirandish F, Ebrahimzade F. Prevalence of intestinal parasites in Lorestan Province, West of Iran. Asian Pacific J Trop Dis. 2014; 4: S728-32.

26. Arani AS, Alaghehbandan R, Akhlaghi L, Shahi M, Lari AR. Prevalence of intestinal parasites in a population in south of
Tehran, Iran. Revista Ins Med Trop São Paulo. 2008; 50 (3): 145-9.

27. Sayyari AA, Imanzadeh F, Bagheri Yazdi SA, Karami H, Yaghoobi M. Prevalence of intestinal parasitic infections in the Islamic Republic of Iran. East Mediterr Health J. 2005; 11 (3): 377-83

28. Saki J, Khademvatan S, Foroutan-Rad M, Gharibzadeh M. Prevalence of intestinal parasitic infections in Haftkel County, southwest of Iran. Int J Inf. 2017; 4 (4): e15593.

29. Sharif M, Daryani A, Kia E, Rezaei F, Nasiri M, Nasrolahei M. Prevalence of intestinal parasites among food handlers of Sari, Northern Iran. Revista Ins Med Trop São Paulo. 2015; 57 (2): 139-44.

30. Abera B, Biadegelgen F, Bezabih B. Prevalence of Salmonella typhi and intestinal parasites among food handlers in Bahir Dar Town, Northwest Ethiopia. Ethiopian J Health Develop. 2010; 24 (1): 46-50

31. Gelaw A, Anagaw B, Nigussie B, Silesh B, Yirga A, Alem $\mathrm{M}$, et al. Prevalence of intestinal parasitic infections and risk factors among schoolchildren at the University of Gondar Community School, Northwest Ethiopia: a cross-sectional study. Bio Med Cen Inf Dis. 2013; 13 (1): 304.

32. Hooshyar H, Bagherian $\mathrm{T}$, Baghbani F. Prevalence of intestinal parasitic infections among patients referred to Kashan reference laboratory in 2007-2011. Jundishapur Sci Med J. 2013; 5 (1): 18-22. 